\title{
Study and Practice on Teaching Reform of Mechatronics Technology Course
}

\author{
Zengsheng Wang \\ School of Mechanical Engineering \\ Huanghe Science and Technology College \\ Zhengzhou, China 450063
}

\author{
Hansong Yang \\ School of Mechanical Engineering \\ Huanghe Science and Technology College \\ Zhengzhou, China 450063
}

\author{
Fating Zhang \\ School of Mechanical Engineering \\ Huanghe Science and Technology College \\ Zhengzhou, China 450063
}

\begin{abstract}
The paper analyzed the present course reform of the mechatronics technology, and carried on the teaching reform practice in three aspects of the mechatronics technology content system, the teaching method and the teaching measure. The paper respectively established curriculum system oriented in project and taking into the content integrity of the system into consideration. By means of joining the exhibitive teaching, it takes thick and thin method, comparative method, analogy method, building knowledge tree as a teaching method reforming measures. It has been proved that the teaching effect of mechatronics technology curriculum has been effectively improved. It could be taken as a reference for teaching reform of mechatronics technology course.
\end{abstract}

Keywords-mechatronics technology; teaching reform; content system; teaching methods; teaching measure

\section{MEChatronics TECHNOLOGY CURRICULUM CHARACTERISTICS}

Mechatronics technology is an important professional course of mechanical design manufacturing and automation, mechanical and electronic engineering, the main teaching of mechatronics system composition, mechanical and electrical system detection technology, mechanical and electrical system content driven technology and the implementation of device, mechanical and electrical system control technology. The curriculum has a wide range of knowledge, difficulty, high comprehensive, feature of strong practice, students often feel the content is abstract, boring, and how to improve the enthusiasm of and the teaching effect has become an important topic urgently need to explore for the teachers.[1]

\section{CURRENT STATUS OF RESEARCH ON THE REFORM OF MECHATRONICS TECHNOLOGY COURSE}

\section{A. Teaching Mode Reform}

Yanshan University adopted the mode of CDIO (conceive, design, implement and operate) on mechatronics system design

This work is supported by the national college students practice base (Higher education secretary [2013]48), Henan Province ordinary university undergraduate engineering education personnel training mode reform pilot (higher education. [2012]964). curriculum, innovative curriculum construction concept constructed by students as the "theoretical teaching, discussion interactive, hands-on experiment, research projects, courses design" five style teaching system, focused on the assessment of learning process, and the comprehensive quality and ability, to achieved the comprehensive training of students' teaching goal. [2]

According to the two main characteristics of the integration of the mechatronics technology curriculum, the combination of knowledge innovation theory and teaching practice experience, Suzhou University had put forward three levels of teaching mode: basic teaching case, innovative practice research and virtual assistant experiment. Teaching practice showed that these measures mobilized the enthusiasm of the students in the limited teaching time, and improved the teaching effect of the course. [3]

\section{B. Practice teaching Reform}

Sichuan University of Science and Engineering proposed a kind of laboratory construction project and talent training model in the practice of independent development of teaching projects. Developed the open practice teaching project, and took the step motor drive device as the content. The project's laboratory input low, low annual digestion, which can be carried out more than 20 projects. [4]

Nanjing University of Aeronautics \& Astronautics established the "mechatronics technology open laboratory". The laboratory has a mechatronics training experimental platform, which is divided into different modules such as power supply, mechanical structure, information processing and control, detection sensing, power control and so on. [5] The school also took the FESTO production line model as the prototype, used the WEB and the virtual reality technology, having developed the virtual automatic production line experiment system based on the computer simulation. [6]At the same time, a comprehensive experimental system based on the transformation of scientific research achievement was developed. The system made full use of the advanced 
technology and research methods. In the experimental model, a comprehensive model was replaced by a single type, the free type replaced the restricted type, and the innovative type replaced the verification type. In the arrangement of the content, focused on order and continuity, highlighting the introduction of advanced technology, research thinking and research methods, which created the conditions for students to master advanced technology and methods, not only to mobilized the students to participate in the initiative of the experiment, but also achieved the goal of scientific research thinking and innovation awareness. [7]

\section{PRACTICE OF MEChATRONICS TECHNOLOGY CURRICULUM REFORM}

\section{A. Reform of Ccurriculum Content System}

Through the market of teaching materials research founded that the current integration of mechatronics technology course content system is not the same. The system composed by some of mechatronics products (system) and took some of the mechantronics of the composition of the technology as the system. Taking into account the various types of mechatronics products, the composition is different, and its common key technology is a certain, that is, mechanical technology, sensing and detection technology, information processing technology, automatic control technology, servo drive technology, system overall technology. So it was determined that the key technology of the six general characteristics of mechatronics is the system to organize the content, to carry on the teaching.

The selection of the specific content of each section should be considered to avoid repeating the course. Such as mechanical technology, with a focus on transmission, guide and support; part of the sensor to mechatronics products common detection (i.e. input, such as displacement, velocity, acceleration and force) as the main line arrangement of content, to distinguish it from the "sensor technology", "test technology" course content.

The curriculum content takes the typical mechtronics project as the guidance. On the basis of sufficient investigation and research,, by screening, compared to account for the moderate difficulty, "working table of the machine tool drive design" as the total project, to guide the book, but at the same time, it decomposes into four sub projects throughout in the corresponding sections, as shown in "Table I" below. MODE [8]

\begin{tabular}{|c|c|c|c|}
\hline Chapter & $\begin{array}{c}\text { General } \\
\text { project }\end{array}$ & Content & Sub project \\
\hline $\begin{array}{l}\text { Chapter } \\
1\end{array}$ & \multirow{6}{*}{$\begin{array}{l}\text { working } \\
\text { table of } \\
\text { the } \\
\text { machine } \\
\text { tool drive } \\
\text { design }\end{array}$} & introduction & I \\
\hline $\begin{array}{l}\text { Chapter } \\
2\end{array}$ & & $\begin{array}{l}\text { Mechanical } \\
\text { transmission in } \\
\text { mechatronics system }\end{array}$ & $\begin{array}{lr}\text { Sub project } & 1: \\
\text { Horizontal } & \text { lathe } \\
\text { numerical } & \text { control } \\
\text { transformation } & \text { feed } \\
\text { transmission } & \\
\text { mechanical } & \text { system } \\
\text { design } & \end{array}$ \\
\hline $\begin{array}{l}\text { Chapter } \\
3\end{array}$ & & $\begin{array}{lr}\text { Composition } & \text { and } \\
\text { interface } & \text { of } \\
\text { mechatronics } & \text { control } \\
\text { system } & \end{array}$ & 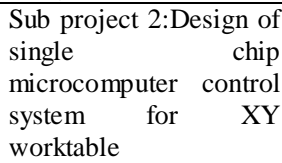 \\
\hline $\begin{array}{l}\text { Chapter } \\
4\end{array}$ & & \begin{tabular}{lr} 
Sensor & \multicolumn{2}{r}{ signal } \\
processing and its \\
interface \\
Microcomputer
\end{tabular} & $\begin{array}{l}\text { Sub project 3:Design of } \\
\text { data acquisition system }\end{array}$ \\
\hline $\begin{array}{l}\text { Chapter } \\
5\end{array}$ & & $\begin{array}{l}\text { Servo system in } \\
\text { mechatronics }\end{array}$ & $\begin{array}{l}\text { Sub project } 4: \text { Ring } \\
\text { distribution system for } \\
\text { stepping motor }\end{array}$ \\
\hline $\begin{array}{l}\text { Chapter } \\
6\end{array}$ & & $\begin{array}{l}\text { Teaching case of } \\
\text { mechatronics project }\end{array}$ & $\begin{array}{l}\text { Other project cases and } \\
\text { student's works }\end{array}$ \\
\hline
\end{tabular}

The above content system has the integrity and rigor of the mechatronics system in the traditional teaching materials. At the same time, it has the characteristics of "project type" teaching material. The sub projects and the total project echo, in the sub project to consider the overall performance requirements of the product, reflecting the mechanical and electrical integration of the concept of "systematic design".

\section{B. The Reform of Teaching Methods and Means}

Teach the students some simple and easy learning methods. In addition to learning textbook knowledge but also read a lot of information, including reference books and network information, to expand the knowledge of mechatronics. To establish the topological relationship between the various parts of knowledge, construct the knowledge structure, form the knowledge system. Finally, the students are required to construct the knowledge tree of the curriculum and draw the knowledge map. Knowledge map is the key words to extract the contents of the course, through the lines, arrows, etc. to connect them, to show the main contents of the course. The form of knowledge topology is also varied, such as linear graph, mesh graph, tree graph (knowledge tree), form, simple strokes and so on. And the knowledge tree can make the students grasp the teaching material system, rationalize the structure of knowledge, understand the status and function of knowledge, and integrate the teaching material to provide visual material.

In the study of specific knowledge point, guide students to use analogy and contrast method, improve learning efficiency. Analogy is the comparison of new things and known things, can be compared with the old knowledge, but also can be compared with the daily life experience. It is not only beneficial to the students' learning of new knowledge, understanding, but also conducive to the complex mechatronic 
conceptual and technical specific, visualization, can help students through the Association for re imagination, thinking seeking clues to get problem solving methods. Contrast method is a method to compare the nature and characteristics of different things in some ways. By comparing different sides of the object to analyze, it forms a sharp contrast to deepen the knowledge of the impression.

At the same time, in order to enhance students' perceptual knowledge of mechanical and electrical products, we put forward the exhibition learning method, which is a practical, feasible and effective way. When we look for companies trying to cognition practice, often encounter the following three questions: first, counterpart of business was difficult to find; the second: enterprise counterparts is not allowed to visit; third: the companies are allowed to visit, but the enterprise's products are single and finite. And the exhibition can solve all the problems: Zhengzhou has a lot of mechantronic related exhibitions every year, and the exhibition is free of charge to the public. There are a lot of different enterprises and mechatronicsl products in the exhibition. In the course of the exhibition, the students have a deeper understanding of the mechantronics knowledge through the perceptual knowledge of mechatronics products. At the same time, in visiting the exhibition to come into contact with the latest technology of mechatronics, such as 3D printing technology, ABB, KUKA, robot technology, and be able to find their own interests lie, to know something about the future work objects and scenes.

In the teaching method, the traditional teaching method and the modern teaching method were combined. Further improved the multimedia material library, including picture library, animation library, video library, case library, exercises, etc.. The instructional design of the course was based on the teaching material as the main line, using the rich multimedia graphics, images, animation, video, audio and network functions, to increase the amount of information.

Scientific and rational used of modern educational technology, the students were encouraged to use advanced design methods and means in normal operations, such as computer aided design, computer graphics, computer simulation, practice teaching into classroom teaching, to cultivate the students' independent analysis and solution actual problem ability.

\section{Extending the Course Teaching to the Outside of the Classroom}

On the one hand, we provided a number of national, provincial excellent curriculum or network curriculum resources website, and some industry websites, forums, Wechat, microblogs and other for students to learn; on the other hand, encouraged students to participate in the creative community activities, to participate in academic competitions, to cultivate innovative consciousness, enhance practical ability. These measures extended the teaching to the outside of the classroom, fully mobilized the enthusiasm of the students learning.

\section{Improving Theteachers Professional Level}

It adopted series of measures to improve the teaching level of teachers. First, held teaching research activities, improve the teaching level. Second, the teacher should not only teach theoretical courses, but also teach the experimental course, make the theory and the experiment closely, improve the teaching effect. Third, teacher training. Support teachers to participate in the training of teachers, teaching seminars, academic conferences, etc.

\section{E. Experimental Teaching Reform}

In order to strengthen the cultivation of students' practical application ability, we had established a new and more reasonable experimental system. The new experimental system from easy to difficult, namely the creation of "verification based", "integrated", "innovation", "design" in the project, the experiment was divided into basis, integration, innovation, design four levels, through experiments to cultivate students to integrate theory with comprehensive practical ability.

\section{F. Follow-Up Reform}

First is textbook construction, especially embodies the characteristics of teaching material, enhance the readability of the textbook and interesting, can add "columns" in the textbooks, such as reading the extension, engineering background and some latest electromechanical integration technology.

The second is to add thecourse design of mechatronics technology. mechatronics technology is a highly practical course.In the course of the curriculum design, the students are required to use the knowledge of mechanical, electronic, computer and automatic control, etc., to carry out a combination of mechanical and electrical design training. Through the curriculum design of training can develop the students 'ability to analyse and solve problem,establish the idea of system design preliminary; can improve student application manuals and standards, consulting literature and to write a scientific paper. [9]

\section{IMPLEMENTATION RESULTS OF TEACHING REFORM}

The results in the school after the implementation of the 2012 students, the same knowledge assessment, compared with the 2011 session, the good rate (80 points or more) increased from $46.30 \%$ to $65.20 \%$, increased by $18.9 \%$. (the data is derived from the school's educational system).

\section{CONCLUSION}

In the reforms of the mechatronics technology course, adopted a project oriented content system, at the same time, it also ensured the integrity and rigor of the knowledge system. The courses are taught using multimedia. In the teaching method, it used the exhibition study method, comparison method, analogy method and so on. The practice has proved that through the teaching reform of the mechantronics technology course, the teaching effect has been improved effectively. 


\section{REFERENCES}

[1] Zhao Limei ,Li Kun.The reform and practice of case teaching in mechatronics technology course[J]. University Education. 2016(3): 106-107.

[2] Zhao Yongsheng, Yao Jiantao, Zheng Kuijing.The construction and practice of teaching system in "mechatronics system design" curriculum[J].Chinese University Teaching, 2010,(3):40-42.

[3] Zhong Bowen Jin Ziqi, Wang Zhenhua.On the teaching mode of Mechatronics course based on knowledge innovation theory[J]. Science and technology vision, 2014,0(34):77-77.

[4] He Qingzhong, Liu Xiaoxu, Tian Jianping. Research on the opening practice project of the stepper motor drive device[J]. Journal of Sichuan University of Science and Engineering: Social Science Edition, 2007,(S1):218-220.

[5] Zhuang Xixing. Exploration and practice of experimental teaching of mechantronics technology[J]. Laboratory Science,2009,(3):37-38. 